\title{
The Impact of Organizational Factors on Nurses Turnover Intention Behavior at Public Hospitals in Jordan: How Does Leadership, Career Advancement and Pay-Level Influence the Turnover Intention Behavior among Nurses
}

\author{
Mohammad Alhamwan ${ }^{1}$, Norazuwa Bt Mat ${ }^{1} \& \operatorname{Imad}$ Al Muala ${ }^{2}$ \\ ${ }^{1}$ College of Business, Universiti Utara Malaysia, Malaysia \\ ${ }^{2}$ Assistant Professor, Faculty of financial and administrative sciences, Al-Ahliyya Amman University, Jordan \\ Correspondence: Mohammad Alhamwan, PhD Candidate, Correspondence, College of Business, Universiti Utara \\ Malaysia, Malaysia. E-mail: malhamwan@yahoo.com
}

$\begin{aligned} & \text { Received: February 4, } 2015 \quad \text { Accepted: March 3, } 2015 \quad \text { Online Published: May 31, } 2015 \\ & \text { doi:10.5539/jms.v5n2p154 }\end{aligned} \quad$ URL: http://dx.doi.org/10.5539/jms.v5n2p154

\begin{abstract}
:
Background: Turnover intention has the possibility to have destructive effects on the life of nurses, healthcare organizations and societies in general. It is considered as one of the major problems that many organizations face, because higher costs and losses could happen because of turnover intention. All over the world, nurses shortage in increase. Organizational factors such as leadership, advancement opportunities, and pay level are among the most connected to the nurses turnover intention.
\end{abstract}

Purpose: The purpose of the study is to explore the relationship between organizational factors (leadership, advancement opportunities, and pay level) and turnover intention.

Design: Six hundred nurses working at public hospitals in Jordan, selected randomly, using survey method.

Findings: This study revealed that there is a significant relationship between leadership and pay level on turnover intention of nurses and insignificant relationship between advancement opportunities and turnover intention among nurses.

Conclusions: This study showed that organizational factors (leadership quality, pay level, and career advancement) are related to turnover intention. As such this study contributes to shedding a light on the activities of human resource management such as work conditions, stress management, and development of anti-turnover policies. This study therefore contributes to turnover intention literature in the context of the Middle East, particularly the healthcare industry is largely dependent on its nurses in enhancing healthcare services for individuals and in developing the industry.

Keywords: turnover intention, leadership, pay-level, advancement opportunities

\section{Introduction}

Turnover intention is one of the major problems that many organizations face, because higher costs and losses could happen as a result of turnover intention, and since there are direct and indirect costs, both costs are critical, complicated, and serious. Direct costs are thing such as replacement, and recruiting temporary staff; indirect costs could be more problematic, such as the moral cost of training and service quality (Morrell et al., 2004). According to one estimate, the cost of employee turnover in the United States of America is around $\$ 5$ trillion annually (Frank et al., 2004).

Nursing workplaces all over the world are one of the densest in the healthcare sector, more than 2 million in US, 1 million in Japan, and in Jordan 16000 RNs, while the total nursing workforce in Jordan is 27300 nurses and midwives. The International Council of Nurses (ICN) and WHO stated respectively in 2002 and 2007 that the situation in the nursing workplace is a crisis one marked as a result of nurse shortages; moreover, in the long-run, the supply of nurses will not be able to top up the shortage, and education programs all over the world are also characterized by the scarcity and lack of nursing faculties (MOH, WHO, 2011). Scott (2001) outlined the consequences of the nurse shortage as a global phenomenon: higher rate of patient morbidity and mortality, failure 
to mitigate patient's pain, poor productivity, and cost containment. Previous studies indicate that voluntary turnover intention is influenced by many factors. Maertz (2001) stated that environmental, individual, structural, and job-related variables have been considered as possible determinants of turnover intention (Price, 2001). Organizational factors such as leadership, advancement opportunities, and pay level are among the most connected to the nursing workforce in Jordan (Hayajneh et al., 2009).

In addition, Najera (2008), who suggested that there were significant differences in intention groups (to leave or to stay), found that promotion was one major issue; moreover, promoting a dialogue is any talk about getting a higher position, or about advancing in their present position. Najera (2008) also suggested that factors like promotion opportunities and bonuses that distinguish and reward employees based on their performance were recognized as significant in determining whether individuals are likely to stay or leave their job. Zhao and Zhou (2008) proposed that career advancement or promotion opportunities had an influence on turnover decision through diverse approaches like current career level, upward mobility, and future career advancement. What's more, Supervisors and managers in nursing workplace are working as model and mentor. They are responsible to deal with, directing and working out all issues in their units along with their job in future planning in the strategic level. Kotter (1999) and Bass (1990) pointed out that there is significant correlation between leadership style and job satisfaction. However, even the direct correlation between turnover intention and leadership behavior is weak but still in somehow a relationship between leadership behavior and turnover intention among nurses. Leadership also has a direct effect on creating a work climate that could affect job satisfaction, and this in turn will affect staff turnover intention.

On the other hand, rewards system in any organization is the technique to barter the employee' services in their efforts to achieve the organization's objectives, by the organization's rewards and compensation system, however, monetary pay is the most common and the most important element. There is no doubt that pay can be the most significant motivation factor, and the best element to encourage the employees to stay and increase the retention level among them (Lum et al., 1998; Bartol \& Locke, 2000; Graham \& Welbourne, 1999). Previous studies have shed the lights on phenomena of increasing the employment turnover rate in the nursing sector as an emerging problem deserving to be considered. the International Council of Nurses (ICN) and World Health Organization (WHO) stated respectively in 2002 and 2007 that the situation in nurses' workplace crisis- one marked as a result of nurse decisive shortage, moreover, in the long run supply of nurses will not be able to top up the shortage, because the education programs all over the world which also Characterized by the scarcity and lack of nursing faculty (Darawad, 2009; Buerhaus et al., 2007).

Additionally, the majority of studies on nurses' intention to leave were conducted in the united states of America and western countries, and a little some in the middle east region. Aiken et al. (2002), in their study about nurses' job satisfaction, pointed out that $41 \%$ of the nurses in the USA and $32.9 \%$ of the Canadian nurses are dissatisfied with their job. If this is the situation in developed countries, what is the situation in developing countries. Moreover, the global turnover rate among nurses is different from year to another. In U.S.A it was $56 \%$ in 2002 , while in UK it was $22 \%$, and in Jordan it was $37 \%$, which means it is a serious problem in Jordan as well as all over the world. It is a critical problem for Jordanian hospitals, however, very few studies have been done to investigate this issue, while the size of this problem keeps getting bigger and bigger in Jordanian hospitals. Moreover, this issue covers the entire health sector of the country. This issue should be deeply investigated, and further studies should be conducted to provide more evidence of the findings of previous studies, and to present better explanations of the factors that affect nurses' turnover intention in Jordan. Besides, future studies should explore the different factors that cause the difference in turnover intention rates in the Jordan nursing workplace where the official unemployment rate in Jordan is around 13.5 per cent (Jordanian National Institute for Training, 2012), while some non-governmental sources claim it is around 20 percent. The situation in Jordanian nursing is no better; according to Hayajneh et al. (2009), the turnover intention rate among Jordanian nurses was $36.6 \%$ (37\% female RNs and $36.2 \%$ male RNs) (Hayajneh et al., 2009). Theoretically, scholars have paid attention into turnover intention or intention to leave toward the actual turnover behavior and the antecedent's factors specifically (Richer, Blanchard, \& Vallerandi, 2002). What is more, turnover intentions has been studied by previous scholars more than actual turnover because both employees and employers are aware of their decision before actually leaving their jobs, to implement a proper prevention policy (Mor Barak, Nissly, \& Levin, 2001; Awang, Amir, \& Osman, 2013). This study aim to investigate the influence of organizational factors (leadership quality, pay level, and career advancement) among nurses (RN's) at public hospitals in Jordan.

\section{Methodology}

The research design refers to the fundamental methods, techniques, and procedures of data collection and analysis (Zikmund, 2010). Thus, a cross-sectional correlational survey is employed. In this study, the registered nurses who 
working in public hospitals in Jordan are requested to respond to items concerning themselves and their work environment through a five-point Likert scale form strongly disagree to strongly agree. Therefore, a questionnaire was developed wherein the statements required the respondents to select the answers from a five point scale encapsulating all the study variables. The survey was designed to measure four instruments employed and adapted from prior studies; advancement opportunities (Landau \& Hammer, 1986), leadership (Ekvall \& Arvonen, 2007), pay level satisfaction (Henerman \& Schwab, 1985), and turnover intention (Takase, 2006). Regarding the reliability of these four instruments as mentioned up, the Cronbach alpha were as following; turnover intention 0.79, (Takase, 2005), advancement opportunities 0.76 (Landau \& Hammer, 1986), leadership reliability between 0.86 and 0.94 in all previous studies (Ekvall \& Arvonen, 1990), and Pay level, Cronbach's alpha was found in three different groups $=0.94,0.95$ (Heneman \& Schwab, 1985).

\subsection{Sampling Design}

The study population is comprised of registered nurses (RNs) working in public hospitals run by the Ministry of Health in Jordan $(\mathrm{MoH})$. A total of 31 hospitals employing 3586 RNs are located in the twelve provinces of the country (MoH, 2011). According to the rule of thumb laid down by Krejcie and Morgan (1970), a sample size of 346 with a confidence level of $95 \%$ and an error level of $5 \%$ is proposed for a population size numbering 3500 .

In Jordan, there are thirty one public hospitals (MoH, 2009), with 3586 registered nurses working in them. These hospitals are located in three regions: the northern, the middle and the southern. For sample selection, the appropriate number of questionnaires to be distributed was determined to be 600 to make get the minimum questionnaires required for data analysis. The study instrument was primarily modified, in terms of language, to align with certain aspects of Jordanian hospitals. Accordingly, back-to-back translation was conducted to match the capabilities, proficiency, and academic background of the respondents.

\subsection{Response Rate}

A total of 600 Jordanian RNs were involved in completing the questionnaire. Of these, 137 questionnaires were not usable because they had not been properly completed the main questions related to turnover intention, and other factors. Owing to the voluntary filling of the questionnaires, some nurses were upfront in their refusal to cooperate, and the nurse section manager was left to apologize for the low rate of response. Additionally, because of the hospital's heavy work load, particularly in the emergency unit, surgery unit, and other units, the nurses did not have enough time to contribute to the research. However, from the 600 distributed questionnaires, 463 were considered appropriate for data analysis (representing a $77 \%$ response rate).

\subsection{Profile of Respondents}

There are seven main items of sample characteristics in this study: gender, age, marital status, professional nursing experience, education, current work position, and number of night shifts per month. The outcome, after analyzing the demographic variables, is presented in this section. The final total sample was comprised of 277 female respondents $(60.2 \%)$ and 183 male respondents $(39.8 \%)$. Among the female nurses, the majority of the study sample study, nearly half $(49.3 \%)$ were between the ages of 20 to 29 years old and nearly two thirds $(64.3 \%)$ were married. The remaining $33.3 \%$ were unmarried and $2.4 \%$ were divorced. A significant proportion of the sample (84.8\%) were employed as RNs while some worked as chief of shift $(6.7 \%)$, chief of nurses $(2.6 \%)$, and supervisors (5.9\%). Additionally, a majority of the nurses (71.3\%) worked more than 4 night shifts in a month and the remaining $30.9 \%$ worked more than 10 night shifts in a month. Of the total sample, $97.2 \%$ hold a bachelor's degree and $2.8 \%$ hold a master's degree. The majority of the sample study (38.5\%) had been working less than five years as nurses; $29.6 \%$ had been working for 6-10 years; $19.1 \%$ had been working for $11-15$ years; $8.5 \%$ had been working for 16-20 years; and finally, a mere $4.3 \%$ had been working for over 2 decades.

\section{Data Analysis}

A factor analysis was used for all dependent and independents variables. Owing to the factor analysis objective of presenting the underlying relationships between variables, if an item in the questionnaire failed to correlate with any of the other items at the level of 0.3 or more, it was not included in the analysis (Kinnear \& Gray, 1999). This step has been taken as a recommendation of Podsakoff, MacKenzie, \& Podsakoff (2012) to insure that the method common variance not occurs. Then, in order to identify the relationship between leadership, pay level, and advancement opportunities and turnover intention, the researcher conducted a multiple regression analysis. In this regard, the multiple correlation $(\mathrm{R})$, the squared multiple regression $\left(R^{2}\right)$, along with the adjusted squared multiple regression $\left(R_{\text {adj }}^{2}\right)$ shows the level to which the combination of independent variables predict the dependent one.

As presented in Table 1.1, the regression equation of all predictions is significant where $R=0.47, R^{2}=0.22, R_{\text {adj }}^{2}$ $=0.21, \mathrm{~F}=18.67, \mathrm{p}<.001$. This shows that multiple coefficients between the predictors and dependent variable is 
$48 \%$ with all predictors constituting $22 \%$ of the variation in turnover intention.

In addition, the model generalizability in another population was at $0.22 \%$. Thus, the $R^{2}$ value showed a decrease of 0.012 in the $R_{a d j}^{2}$, evidence that the model's cross validity is fine. Based on the significant F-test, the relationship between the dependent and independent variables is linear with the dependent variable significantly predicted by the model. In detail, the F-test result $[\mathrm{F}=18.67, \mathrm{p}<.001]$ indicated the overall prediction of the independent variable of the dependent one despite the lack of information concerning the significance of every individual independent variable. Each predictor's contribution is displayed in Table 1.1 and reflects the standard regression weight of each predictor in the regression equation (Green and Salkind, 2008). Among the six predictors, the greatest and most significant standardized beta coefficient was displayed by depressive symptoms $(\beta=.20, \mathrm{t}=4.13$, $\mathrm{p}=.001)$, indicating that it is the most significant turnover intention predictor. This is followed closely by discrepancy $(\beta=.19, \mathrm{t}=4.17, \mathrm{p}=.001)$, leadership $(\beta=-.18, \mathrm{t}=-3.63, \mathrm{p}=.001)$, pay level $(\beta=-.13, \mathrm{t}=-2.77, \mathrm{p}=.001)$.

Overall, the six-predictor variables impacted the dependent variable in the manner postulated in the hypotheses. Thus, it can be stated that turnover intention occurs when nurses perceive a high role of discrepancy, high depressive symptoms, high work/home interference, low leadership, low advancement opportunities, and finally, low level of pay. The entire hypotheses from 1-6 are supported by the study findings.

Table 1. Result of regression analysis

\section{Coefficient}

\begin{tabular}{|c|c|c|c|c|c|c|}
\hline \multicolumn{2}{|c|}{ Model } & \multirow[t]{2}{*}{ Beta } & \multirow{2}{*}{$\frac{\mathrm{T}}{6.748}$} & \multirow{2}{*}{$\frac{\text { Sig. }}{.000}$} & \multirow[t]{2}{*}{ VIF } & \multirow{2}{*}{$\frac{\text { Durbin-Watson }}{1.764}$} \\
\hline 1 & (Constant) & & & & & \\
\hline & Leadership & -.176 & -3.631 & .000 & 1.175 & \\
\hline & Pay level & -.133 & -2.770 & .006 & 1.158 & \\
\hline & Advancement opportunities & -.092 & -1.924 & .055 & 1.153 & \\
\hline
\end{tabular}

Note. $\mathrm{R}=0.47, R^{2}=0.22, R_{a d j}^{2}=0.21, \mathrm{~F}=18.67$

\section{Discussion}

This study proposed that leadership negatively impacts turnover intention. Leadership is the primary factor that can drive the organization to achieve its objectives and enhance its advantage among its competitors (Zhu et al., 2005). In the present study, the researcher examines leadership among nurses in terms of its degree of importance in their stressful work environment and its effect on turnover intention. Based on the finding, leadership impacts turnover intention significantly and this is consistent with the claims of prior researchers who dedicated their work to the nature and premise of the relationship of leadership style to an employee's turnover relationship. Similarly, Bass (1990) stated that the majority of prior studies reported that leadership behavior could be crucial in decreasing and justifying the phenomenon of staff turnover intention. Additionally, leadership style was found to be related to employee's turnover intention among staff for various firms and organizations including hospitals. A significant relationship was measured between leadership style and turnover intention in the context of nurses (i.e. Bycio, 1995).

This finding is consistent with those reported by Bass (1990), Awan and Mahmood (2010), Riaz and Haider (2010), Zhu et al. (2005), Sellgren et al. (2007), Albaugh (2003), Greco et al. (2006), Sellgran et al. (2007) and Cook (2001). Specifically, Sellgren et al. (2007) demonstrated a significant correlation between leadership style and job satisfaction in the context of nurse work settings. Although the direct relationship found between turnover intention and leadership style is weak, the relationship still exists. In addition to this, leadership was reported to have a direct impact on development of work climate, and eventually on job satisfaction and staff turnover intention. In a similar line of study, Wells and Peachey (2011) examined the nature of the relationship strength between leadership style and turnover intention among 200 U.S. national colleges and reported a strong negative relationship between leadership style and turnover intention. In similar contexts, Sellgren et al. (2007) reported a significant relationship between styles of leadership and organizational work environment, and they stressed the relationship's significance in terms of the correlation between work environment, work climate, and job satisfaction level, which eventually impacts nursing turnover behavior. Moreover, nursing supervisors or managers have distinct roles in nurse retention and their turnover behavior indicating leadership styles effect on employees' turnover intention, as mediated by job satisfaction.

Regarding the pay level, this study's findings showed that it is negatively related to turnover indicating that nurses 
with high pay are not as susceptible to experiencing turnover intention in comparison to those with low pay. This finding is aligned with those of past findings by Lum et al. (1998), Tekleab et al. (2005), Bergmann and Scarpello (2001), and Gerhart and Rynes (2003). Lum et al. (1998) contended that pay could be the top significant motivation for employees' increased retention. Majority of studies of this caliber focused on the effect of just compensation's impact on employee turnover intention. The results confirmed that dissatisfied employees in terms of low salaries will be more inclined to quit their jobs. In fact, the majority of turnover intention research models assume pay satisfaction to be a main component that affects the inclination of the employees to quit the organization and eventually, display turnover behavior (Tekleab et al., 2005). A number of related researches reported a negative relationship between pay level satisfaction and the turnover intention of employees (Lum et al., 1998).

Along the same line of argument, the pension plan and fringe benefits plans including child care, elder care, food services, and travel, bring about job satisfaction and enhances employee retention while mitigating turnover intention (Lee et al., 1996). Lee et al. (1996) added that investing in human resources through pay and benefit plans significantly impacts the decrease of turnover intention and voluntary turnover. Data analysis of the descriptive statistics the mean obtained from 403 nurses concerning their pay level is 2.770 indicating that the level of pay among Jordanian nurses employed in public hospitals is moderate and it has a negative effect. Nurses employed in public hospitals are often female nurses. In addition, in the present study, most of the respondents are married and this shows the need for high pay level, specifically those appropriated for life expenses, family size, and family duties. This statement holds true as Jordanians are primarily family oriented and their lives revolve around social activities (Al Muala, 2013).

Furthermore, the results of the relationship between advancement opportunities and turnover intention are insignificant. Stated clearly, advancement opportunities did not significantly impact the turnover intention of Jordanian nurses. In this regard, prior studies provided mixed results. Zhao and Zhao (2008) conducted an empirical statistical analysis of over 300 bank employees in Taiwan. They found that job advancement and promotion failed to contribute to turnover intention. Both job advancement and promotion failed to mitigate turnover intention among Taiwanese nurses. Advancement opportunities primarily entail dynamic intra-organizational processes while the tendency of the employee changes over time. Following a structural overview of the career advancement opportunities, the importance of job ladder on turnover intention is highlighted as some professions, like nursing, are characterized by confined advancement opportunities which paint a drab picture of the employees' status advancement. Hence, such advancement opportunities neither positively nor negative impacts turnover intention. Meanwhile, Trevor et al. (1997) and Salamin and Hom's (2005) study in the context of the U.S. and Switzerland respectively focused on examining the curvilinear relationship between job performance and turnover intention and the influence of salary increments and advancement opportunities. Both studies reported that salary minimized the turnover intention among employees. Both studies also reported that the relationship between advancement opportunities and turnover intention did not exist, justified by the fact that nursing is a profession characterized by limited career opportunities and minimal advancement opportunities. The present study extended the research scope of the above studies in that it examines the advancement opportunities structure and its influence on turnover intention in a specific cultural environment, in this case, Jordan. In the Middle East, traditional culture stresses hierarchical order and authority in the society (Farh et al., 1997). Hence, a high job status can be highly coveted, which may play a major role in the intention of the employee to quit. In addition to this, the interpersonal relationship, particularly the supervisor-subordinate relationship, can significantly impact the turnover decision of the employee. Also, career advancement is formed by the career path structure, consisting of graded levels often categorized into job hierarchy (Petersen et al., 1989). In this regard, structured job positions frequently entail different upward mobility prospects. Specifically, an intentionally designed job ceiling position (the top position of the job echelons), often divides job lines related to various job functions, e.g. non-managerial vs. managerial duties.

In other words, a job ceiling creates a significant structural hindrance to status advancement via promotion as only a small number of candidates will be included in the higher echelons. According to March and Simon (1958, p. 97), at a specific point in a promotion ladder, there is considerable decrease in the percentage or absolute increment. Hence, the discontent and lack of interest in promotion will fail to affect the turnover intention of nurses. Furthermore, other empirical researchers also supported that promotion opportunities impact turnover intention in other sectors (Peterson et al., 1989; Scholl, 1983). Based on this premise, it can be argued that despite the fact that the nursing professional subsidiary is promising in Jordan, particularly for female candidates, the future career advancement scenario is quite dark and, hence, does not affect nurses' turnover intention. 


\section{Conclusion}

This study contributes to literature by examining organizational factors (leadership, pay level, and advancement opportunities) as antecedents of turnover intention among nurses. This study showed that organizational factors (leadership quality, pay level, and career advancement) are related to turnover intention. As such this study contributes to shedding a light on the activities of human resource management such as work conditions, stress management, and development of anti-turnover policies. The finding that evidenced the relationship between organizational factors and turnover intention has implications on the above activities. This information may help human resource professionals to assess work conditions and identify the source and reason behind turnover. Specifically, employees experiencing low leadership quality, pay level, and advancement opportunities are susceptible to negative behavior such as turnover intention.

Theoretically, turnover intention is a topic that has been exhausted in the West but has been largely overlooked in the Middle East. This study therefore contributes to turnover intention literature in the context of the Middle East, particularly Jordan and offers an understanding of turnover intention among nurses employed in public hospitals. It is suffice to say that the healthcare industry is largely dependent on its nurses in enhancing healthcare services for individuals and in developing the industry as a whole as Jordan is one of the most popular treatment destinations in the region. Moreover, studies dedicated to examining organizational factors (leadership, pay level, and advancement opportunities) have largely been ignored in Jordan prior to the present study, which is in itself a great contribution in terms of theory.

\section{References}

Albaugh, J. (2003). Keeping nurses in nursing: the profession's challenge for today. Urologic Nursing, 23(3), 193.

Al-Muala, I. M. (2013). The moderating effect of personality on the relationship between job demand and job control on workplace bullying among nurses in Jordan (Unpublished doctoral thesis). Universiti Utara Malaysia, Malaysia.

Awan, M. R., \& Mahmood, K. (2010). Relationship among leadership style, organizational culture and employee commitment in university libraries. Library management, 31(4/5), 253-266. http://dx.doi.org/10.1108/01435121011046326

Awang A., Amir A., \& Osman W. (2013). Job Behavioral Factors and Turnover Intention: A Case Study at Sime Darby Property Limited. International Journal of Advances in Management and Economics, 6(2), 103-115.

Bartol, K. M., \& Locke, E. A. (2000). Incentives and motivation. Compensation in organizations: Current research and practice, 104-147.

Bass, B. M. (1990). From transactional to transformational leadership: Learning to share the vision. Organizational dynamics, 18(3), 19-31. http://dx.doi.org/10.1016/0090-2616(90)90061-S

Bergmann, T. J., \& Scarpello, V. G. (2001). Compensation Decision Making (4th ed.). Fort Worth: Harcourt Inc.

Buerhaus, P. I., Auerbach, D. I., \& Staiger, D. O. (2007). Recent trends in the registered nurse labor market in the US: Short-run swings on top of long-term trends. Nursing Economics, 25(2), 59.

Bycio, P., Hackett, R. D., \& Allen, J. S. (1995). Further assessments of Bass's (1985) conceptualization of transactional and transformational leadership. Journal of applied psychology, 80(4), 468. http://dx.doi.org/10.1037/0021-9010.80.4.468

Darawad, M. W. (2009). An Examination of the Role Discrepancy, Depressive symptoms, and Turnover Intention among the Jordanian Nursing Workforce. Case Western Reserve University.

Farh, J. L., \& Cheng, B. S. (2000). A cultural analysis of paternalisticleadership in Chinese organizations. In J. T. Li, A. S. Tsui, \& E. Weldon (Eds.), Management and Organizations in the Chinese Context (pp. 84-127). London, U.K.: Macmillan Press Ltd.

Frank, F. D., Finnegan, R. P., \& Taylor, C. R. (2004). The race for talent: retaining and engaging workers in the 21 st century. Human Resource Planning, 27(3), 12-25.

Gerhart, B., \& Rynes, S. (2003). Compensation: Theory, evidence, and strategic implications. SAGE Publications Incorporated.

Graham, M. E., \& Welbourne, T. M. (1999). Gainsharing and women's and men's relative pay satisfaction. Journal $\begin{array}{llll}\text { of } \quad \text { Organizational } & \text { Behavior, } & \text { 1027-1042. }\end{array}$ http://dx.doi.org/10.1002/(SICI)1099-1379(199912)20:7<1027::AID-JOB957>3.0.CO;2-O 
Greco, P., Laschinger, H. K. S., \& Wong, C. (2006). Leader empowering behaviours, staff nurse empowerment and work engagement/burnout. Nursing Leadership, 19(4), 41-56. http://dx.doi.org/10.12927/cjnl.2006.18599

Hayajneh, Y. A., AbuAlRub, R. F., Athamneh, A. Z., \& Almakhzoomy, I. K. (2009). Turnover rate among registered nurses in Jordanian hospitals: an exploratory study. International Journal of Nursing Practice, 15(4), 303-310. http://dx.doi.org/10.1111/j.1440-172X.2009.01758.x

Heneman, H. G., \& Schwab, D. P. (1985). Pay satisfaction: its multidimensional nature and measurement. International Journal of Psychology, 20, 129-41.

Hussain Haider, M., \& Riaz, A. (2010). Role of transformational and transactional leadership with job satisfaction and career satisfaction. Business and Economic Horizons, (1), 29-38.

Kotter, J. P. (1999). John P. Kotter on what leaders really do. Harvard Business Press.

Landau, J., \& Hammer, T. H. (1986). Clerical employees' perceptions of intraorganizational career opportunities. Academy of Management Journal, 29, 385-404. http://dx.doi.org/10.2307/256194

Lee, T. W., Mitchell, T. R., Wise, L., \& Fireman, S. (1996). An unfolding model of voluntary employee turnover. Academy of Management Journal, 39(1), 5-36. http://dx.doi.org/10.2307/256629

Lum, L., Kervin, J., Clark, K., Reid, F., \& Sirola, W. (1998). Explaining nursing turnover intent: job satisfaction, pay satisfaction, or organizational commitment? Journal of Organizational Behavior, 19(3), 305-320. http://dx.doi.org/10.1002/(SICI)1099-1379(199805)19:3<305::AID-JOB843>3.0.CO;2-N

Maertz, C. (2001). Why employees stay with or quit an organization. Paper presented at the 61st Annual Meeting of the Academy of Management, Washington, DC.

March J. G., \& Simon H. A. (1958). Organizations. New York: Wiley.

MoH. (2009). Annual Statistical Report: Ministry of Health in Jordan (MoH).

MoH. (2011). Annual Statistical Report: Ministry of Health in Jordan (MoH).

Mor Barak, M., Nissly, J., \& Levin, A. (2001). Antecedents to retention and turnover among child welfare, social work, and other human service employees: What can we learn from past research? A review and metanalysis. The Social Service Review, 75(4), 625-661. http://dx.doi.org/10.1086/323166

Morrell, K. M., Loan-Clarke, J., \& Wilkinson, A. J. (2004). Organisational change and employee turnover. Personnel Review, 33(2), 161-173. http://dx.doi.org/10.1108/00483480410518022

Najera, M. (2008). Dialogue with Mexican maquiladora workers: why do they leave and why do they stay? International Journal of Commerce and Management, 18(3), 289-302. http://dx.doi.org/10.1108/10569210810907182

Petersen, T., \& Spilerman, S. (1990). Job quits from an internal labor market. Event history analysis in life course research, 17, 69-95.

Podsakoff, P. M., MacKenzie, S. B., \& Podsakoff, N. P. (2012). Sources of method bias in social science research and recommendations on how to control it. Annu. Rev. Psychol., 63, 539-569. http://dx.doi.org/10.1146/annurev-psych-120710-100452

Price, J. L. (2001). Reflections on the determinants of voluntary turnover. International Journal of Manpower, 22(7), 600-624. http://dx.doi.org/10.1108/EUM0000000006233

Richer, S. F., Blanchard, C., \& Vallerandi, R. J. (2002). A Motivational Model of Work Turnover. Journal of Applied Social Psychology, 32(10), 2089-2113. http://dx.doi.org/10.1111/j.1559-1816.2002.tb02065.x

Salamin, A., \& Hom, P. W. (2005). In search of the elusive U-shaped performance-turnover relationship: are high performing Swiss bankers more liable to quit? Journal of Applied Psychology, 90(6), 1204. http://dx.doi.org/10.1037/0021-9010.90.6.1204

Scott, W. (2001). Nurse workforce: condition critical. Issue Brief, 763, 2-9.

Sellgren, S., Ekvall, G., \& Tomson, G. (2007). Nursing staff turnover: does leadership matter? Leadership in Health Services, 20(3), 169-183. http://dx.doi.org/10.1108/17511870710764023

Takase, M., Maude, P., \& Manias, E. (2006). The impact of role discrepancy on nursesâ€ $€^{\mathrm{TM}}$ intention to quit their jobs. Journal of clinical nursing, 15(9), 1071-1080. http://dx.doi.org/10.1111/j.1365-2702.2005.01508.x

Tekleab, A. G., Takeuchi, R., \& Taylor, M. S. (2005). Extending the Chain of Relationships among Organizational 
Justice, Social Exchange, and Employee Reactions: The Role of Contract Violations. Academy of Management Journal, 48(1), 146-157. http://dx.doi.org/10.5465/AMJ.2005.15993162

Trevor, C. O., Gerhart, B. A., \& Boudreau, J. W. (1997). Voluntary turnover and job performance: Curvilinearity and the moderating influences of salary growth and promotions. CAHRS Working Paper Series, 145. http://dx.doi.org/10.1037/0021-9010.82.1.44

Wells, J. E., \& Peachey, J. W. (2011). Turnover intentions: Do leadership behaviors and satisfaction with the $\begin{array}{llll}\text { leader matter? Team Performance } & \text { Management, }\end{array}$ http://dx.doi.org/10.1108/13527591111114693

Zhao, W., \& Zhou, X. (2008). Intraorganizational career advancement and voluntary turnover in a multinational bank in Taiwan. Career Development International, 13(5), 402-424. http://dx.doi.org/10.1108/13620430810891446

Zhu, W., Chew, I. K., \& Spangler, W. D. (2005). CEO transformational leadership and organizational outcomes: The mediating role of human capital-enhancing human resource management. The Leadership Quarterly, 16(1), 39-52. http://dx.doi.org/10.1016/j.leaqua.2004.06.001

\section{Copyrights}

Copyright for this article is retained by the author(s), with first publication rights granted to the journal.

This is an open-access article distributed under the terms and conditions of the Creative Commons Attribution license (http://creativecommons.org/licenses/by/3.0/). 